\title{
Cervical spondylotic myelopathy treated with corpectomy: technique and results in 44 patients
}

\author{
Sait Naderi, M.D., Cary D. Alberstone, M.D., Frederick W. Rupp, M.D., Edward C. Benzel, M.D., \\ and Nevan G. Baldwin, M.D.
}

Department of Neurosurgery, Marmara University, School of Medicine, Istanbul, Turkey; and Division of Neurosurgery and Department of Radiology (Neuroradiology Section), University of New Mexico School of Medicine, Albuquerque, New Mexico

Forty-four patients with cervical spondylotic myelopathy who underwent a ventral surgical approach were evaluated with respect to the results of surgery. The neurological status of the patients was categorized according to the modified Japanese Orthopedic Association scale (0-18). Three patients had a functional score of 8 , one patient 9 , five patients 10 , five patients 11 , seven patients 12 , seven patients 13 , seven patients 14 , and nine patients had a functional score of 15 , preoperatively. Twenty-three patients underwent a one-level corpectomy, 15 patients a two-level corpectomy, and six patients underwent a three-level corpectomy. Forty-one $(93.1 \%)$ of the 44 patients underwent ventral cervical plate fixation. Complications among the 44 patients included graft- and instrumentation-related complications in seven cases, iliac crest donor-site infection in three cases, and respiratory complications in three cases. The follow-up periods ranged between 7 and 60 months (mean 42.3 months). Overall, the fusion rate was $97.72 \%$. Three patients showed no functional change (6.8\%), two patients were worse $(4.5 \%)$, and 39 patients $(88.6 \%)$ showed functional improvement in their score between +1 and +6 points (mean 2.16 points). There was no statistically significant difference in the functional improvement score in patients younger or older than 60 years old. The mean improvement in the functional score was found to be $+2.857 \pm 1.352,+2.400 \pm 1.454$, and $+0.5000 \pm 1.871$ following one-level corpectomy, two-level, and three-level corpectomies, respectively. There were statistically significant differences in the neurological improvement observed between patients with one-level corpectomy and three-level corpectomy $(\mathrm{p}<$ $0.01)$, as well as between those with two-level and three-level corpectomy $(\mathrm{p}<0.05)$. There was no statistically significant difference in the neurological outcome between patients with one-level and two-level corpectomy ( $p>0.05)$. The results of this study demonstrate a high rate of solid bone fusion and a high rate of functional (neurological) improvement. Five patients underwent reoperation, predominantly for instrumentation failure. The use of instrumentation dictates careful consideration of the risk/benefit ratio associated with its use in each case.

Key Words * cervical spondylotic myelopathy * corpectomy * spinal instrumentation * ventral approach

A variety of ventral and dorsal approaches are used in the surgical management of multilevel cervical spondylotic myelopathy (CSM). The choice of surgical procedures, including laminectomy (with or 
without fusion), laminoplasty, ventral discectomy with fusion, and corpectomy with fusion (with or without instrumentation), remains controversial. It is not always possible to compare the results of ventral and dorsal approaches, because the indications for ventral and dorsal surgery may differ depending on the presence of "effective kyphosis or lordosis" and the location of the compressive lesion (predominantly ventral or dorsal).[1-3,11,12,14-18,19,21] To investigate this decision-making process, we report the results of 44 consecutive patients in whom corpectomy (via a ventral approach) was performed for the treatment of CSM.

\section{CLINICAL MATERIAL AND METHODS}

\section{Patient Population}

There were 34 men, and 10 women. The patients ranged in age from 40 years to 79 years (mean 55.1 years). Fourteen of the patients were 60 years of age or older, and 30 patients were 59 years of age or younger.

Two patients had been treated with a laminectomy and one patient had previously undergone a Cloward procedure (two operations). Three patients had a history of gout. Two patients had a history of mild trauma 6 months prior to hospitalization for their current disease.

Forty-four patients with CSM or radiculomyelopathy underwent decompression and stabilization of the cervical spine via a ventral approach. Patients with congenital cervical stenosis, soft-disc herniation, or those with radiculopathy alone (no myelopathy) were excluded from this study. All of the operations were performed between February 1991 and February 1996 at the University of New Mexico Health Sciences Center and its affiliated hospitals. The surgical procedure consisted of decompression (corpectomy plus foraminotomy) and interbody bone graft insertion, with or without instrumentation.

The indications for choosing the ventral approach were the presence of ventral compressive pathology that correlated with the patient's symptoms and signs, and/or the presence of effective kyphosis or a straightend spine based on lateral plain radiographic measurements.

Diagnostic modalities consisted of plain radiographs of the cervical spine (anteroposterior, lateral neutral, hyperflexion, and hyperextension), magnetic resonance imaging, and computerized tomography scanning. 


\begin{tabular}{|c|c|}
\hline \multicolumn{2}{|c|}{$\begin{array}{c}\text { TABLE } 1 \\
\text { MODIFIED JAPANESE ORTHOPED K ASSOC ATION CERVICAL SPINE MVELOPATHY } \\
\text { FUNCTIONAL ASSESSMENT SCALE }\end{array}$} \\
\hline Sc ore & Defirition \\
\hline \multicolumn{2}{|c|}{ Motor dysfunction score of the upper extremities } \\
\hline & inatility to move hands \\
\hline & inatility to eat w/a spoon, but able to move hands \\
\hline & inatility to button shirt, but able to eat w/a spoon \\
\hline & able to button shirt wigreat difficulty \\
\hline & able to button shirt w/slight difficulty \\
\hline 5 & no dystunction \\
\hline \multicolumn{2}{|c|}{ Motor dysfunction score of the lover extremities } \\
\hline 0 & complete loss of motor \& sensory function \\
\hline 1 & sensory preser vation wib ability to mo ue legs \\
\hline 2 & able to move legs, but unatle to malk \\
\hline 3 & able to walk on flat floor w/ a malking aid (cane or crutch) \\
\hline 4 & able to malk up andibr down stairs in' hand rail \\
\hline 5 & $\begin{array}{l}\text { moderate-to-significant lack of stability, but able to malk up andibr } \\
\text { down stairs wh hand rail }\end{array}$ \\
\hline$\frac{6}{7}$ & $\begin{array}{l}\text { mild lack of stability but walks w' sm ooth reciprocation unajded } \\
\text { no dysunction }\end{array}$ \\
\hline \multicolumn{2}{|c|}{ Sensory dystunction score of the upper extremities } \\
\hline 0 & complete loss of hand sensation \\
\hline 1 & severe sensoryloss or pain \\
\hline 2 & mild sensoryloss \\
\hline 3 & no sensoryloss \\
\hline \multicolumn{2}{|c|}{ Sphincter dysfunction score } \\
\hline 0 & inability to micturate woluntarily \\
\hline 1 & marked difficulty w'micturation \\
\hline 2 & mild-to-moderate difficulty w/ micturation \\
\hline 3 & normal micturation \\
\hline
\end{tabular}

The functional state of the patients was evaluated using the modified Japanese Orthopedic Association (JOA) CSM functional assessment scale (modified JOA scale; Table 1),[3] and the differences between pre- and postoperative scores were determined.

\section{Surgical Technique for One-Level Corpectomy}

After endotracheal intubation and induction of general anesthesia, the patient is placed supine. The authors prefer to operate from the patient's right side, despite the increased risk of recurrent laryngeal nerve palsy. In our view, the benefits of improved access for the right-handed surgeon outweigh the risks of a right-sided approach. The endotracheal cuff pressure is maintained at just above air leak threshold. Using this regimen, recurrent laryngeal nerve palsies have not been observed.

For one- or two-level corpectomy, a transverse skin incision is prefered. For three-level corpectomy, an oblique skin incision along the ventromedial border of the right sternocleidomastoid muscle is performed. This oblique incision allows exposure of the cervical spine from C-3 to T-1. After the appropriate spinal level is confirmed by intraoperative radiographs, a subperiostal dissection technique is used to retract the longus colli muscles laterally to each side of the midline. After placement of a table-mounted retractor, the anterior longitudinal ligament is incised. Using curettage and pituitary forceps, the intervertebral discs above and below the corpectomy level are removed. A high-speed air drill (Midas Rex, Fort Worth, TX) is used to drill away the vertebral body. The remnant of the posterior longitudinal ligament is identified and dissected away. Beginning with the endplate of the rostral end of 
the corpectomy site (superior endplate of the adjacent vertebra), the posterior vertebral body margin is followed laterally from the midline toward each side, using a small upward-angled curette. This identifies the uncinate processes that form the ventral wall of the neural foramen. The uncinate processes are removed and generous foraminotomies are thereby created. In multilevel cases, dissection then proceeds rostally, taking advantage of the known position of the adjacent foramina. Having satisfactorily decompressed the neural elements, a bone graft is taken from the right iliac crest. The mortises in the rostral and caudal vertebral bodies are then prepared with the high-speed air drill, and the harvested bone graft is fashioned to fit snugly. The bone graft is tapped into position, and radiographic evaluation is performed to assess adequate placement. Following placement of the bone graft, a unicortical locking plate is placed. After surgery, a hard collar is prescribed for 6 weeks.

The procedure for two- or three-level corpectomies is similar. Strut grafts are placed into the mortises, while cervical distraction is applied.

Follow-up evaluations were performed at 1, 3, 6, and 12 months after operation, at which time the progress of the fusion and the neurological status of the patient were documented.

Fusion was defined as the presence of crossing trabeculae from the adjacent vertebral bodies to the bone graft and the absence of movement with dynamic (hyperflexion and hyperextension) radiographs. The neurological assessment score of the last neurological examination was used as the measure of final outcome.

\section{Statistical Analysis}

Differences between the pre- and postoperative neurological functional scores were compared statistically using a one-way analysis of variance (ANOVA) with Tukey's post-hoc pairwise comparisons.

\begin{tabular}{|cc|}
\hline & TABLE 2 \\
THE PREOPERAT NE NEUROLOGICAL ASSESSMENT AND SCORE OF THE PATIENTS \\
ACCORD NG TO JOA-CSM NEUROLOGICAL ASSESSMENT SCALE \\
\hline \hline Sc ơ e & No. of Patierts \\
\hline 8 & 3 \\
9 & 1 \\
10 & 5 \\
11 & 5 \\
12 & 7 \\
13 & 7 \\
14 & 7 \\
15 & 9 \\
\hline
\end{tabular}

\section{RESULTS}

On the basis of the modified JOA scale, three patients had a functional score of 8 , one patient 9 , five patients 10 , five patients 11 , seven patients 12 , seven patients 13 , seven patients 14 , and nine patients had a functional score of 15 preoperatively (Table 2). 


\begin{tabular}{|cc|}
\hline TABLE 3 & \\
OPERATIVE PROCEDURE IN PATIENTS WITH CSM \\
\hline \hline Procedure & No. of Patierts \\
\hline one-le vel corpectomy & 23 \\
using iliac crest graft + plate & 20 \\
using iliac crest graft alone & 3 \\
two-level cor pectomy & 15 \\
using iliac crest graft + plate & 6 \\
three-level corpectomy & 6 \\
\hline
\end{tabular}

All patients underwent a standard ventral surgical procedure. Twenty-three patients underwent a one-level corpectomy, 15 patients a two-level corpectomy, and six patients underwent a three-level corpectomy (Table 3). An interbody bone graft was placed in all cases. Autologous tricortical iliac crest bone grafts were used in 39 patients and cadaveric fibula was used in five patients. Forty-one (93.1\%) of the 44 patients underwent ventral cervical plate fixation. An Orion plate (Sofomar Danek, Memphis, TN) was used in 29 patients, a Synthes plate (Synthes Corp., Paoli, PA) in 10 patients, an Acromed plate (Acromed, Cleveland, $\mathrm{OH}$ ) in one patient, and a Codman plate (Johnson and Johnson Professional, Inc., New Brunswick, NJ) in one patient. Figure 1 shows the postoperative radiographs in the two representative cases.

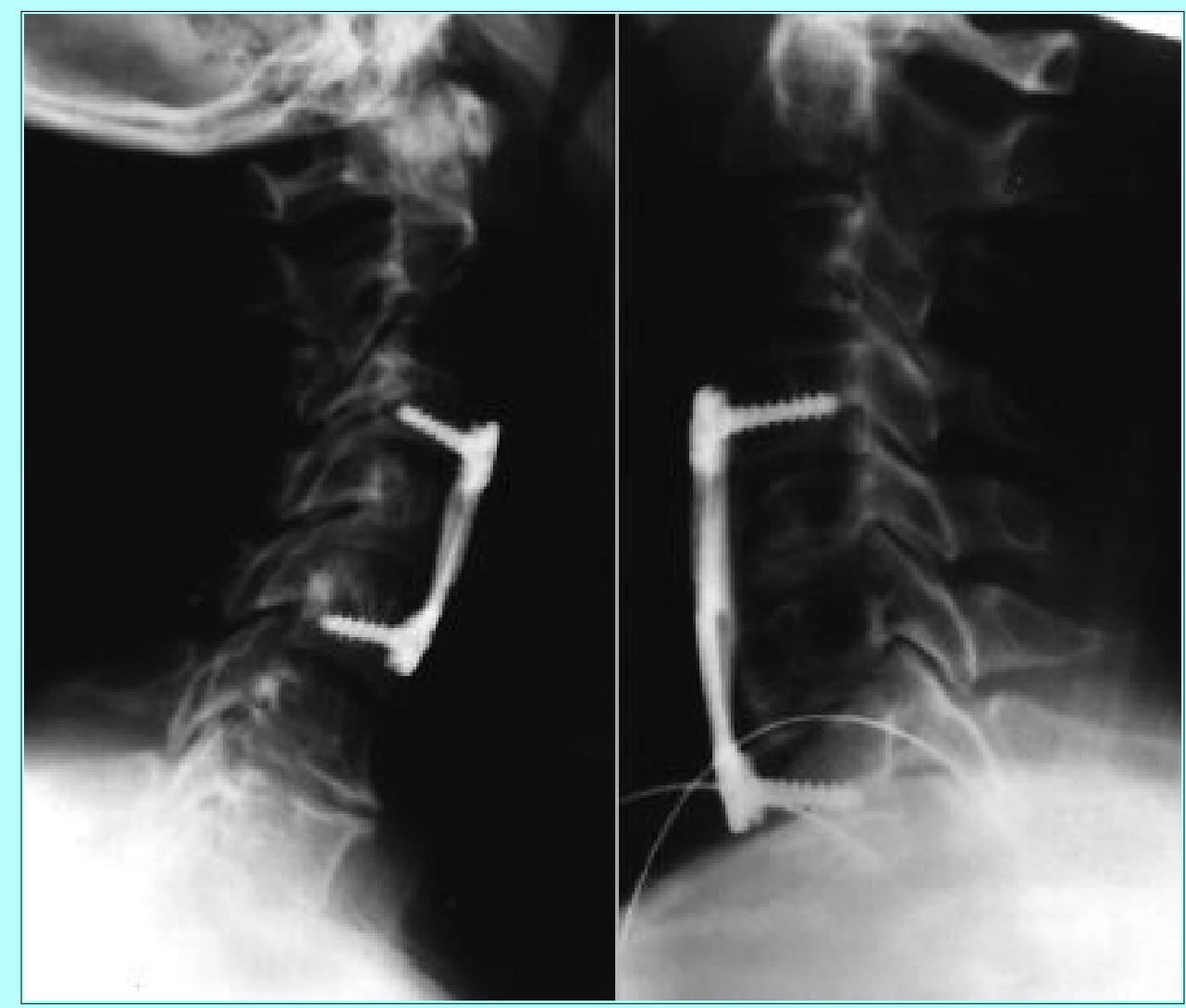

Fig. 1. Left: Postoperative radiograph obtained in a patient with CSM who underwent a one-level corpectomy. Right: Postoperative radiograph obtained in a patient who underwent a two-level corpectomy, with a straightened cervical spine.

Complications among the 44 patients included graft- and instrumentation-related complications in seven cases, iliac crest donor-site infection in three cases, and respiratory complications in three cases (Table 4). 


\begin{tabular}{|cc|}
\hline \multicolumn{2}{c|}{ TABLE 4 } \\
COMPL ICATIONS OF YEN TRAL OPERATION \\
\hline \hline Complication & No. of Patierks \\
\hline screm back-out & 4 \\
screw mal position & 1 \\
pate fracture & 1 \\
nonunion & 1 \\
donor-site infection & 3 \\
pulmonary embolism & 1 \\
respiratory failure & 2 \\
\hline
\end{tabular}

Respiratory complications consisted of pulmonary embolism in one case and upper airway complications in two cases. A respiratory arrest, caused by upper airway obstruction, required reintubation in one patient (this led to cerebral hypoxia). The other patient who was reintubated because of hypersecretion subsequently improved.

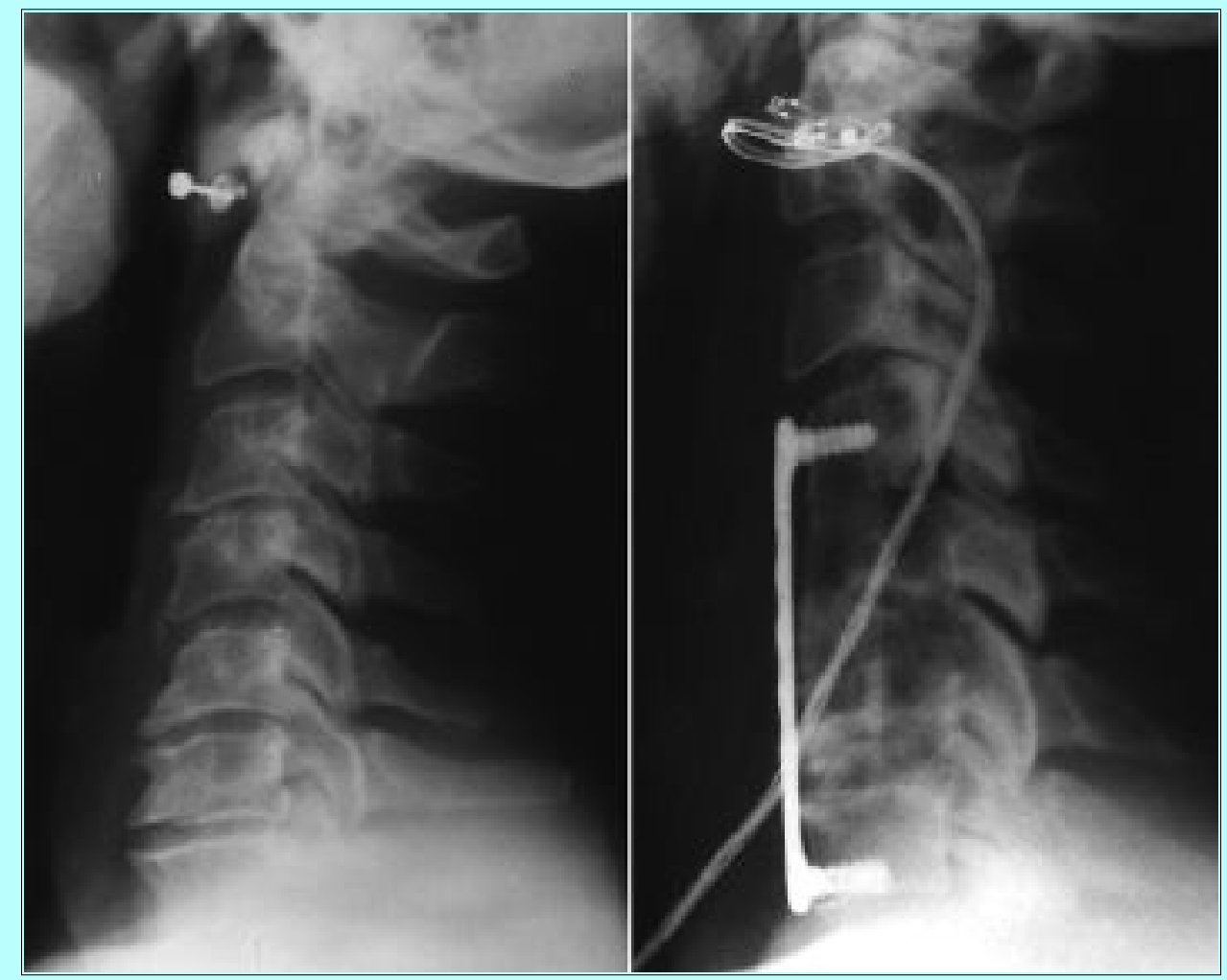

Fig. 2. Preoperative (left) and postoperative (right) radiographs obtained in a patient with CSM. Note that the caudal screw is placed close to the disc space.

Graft- and instrumentation-related complications included four cases of screw back-out. In one case of two-level corpectomy, movement of the bone graft and minimal screw back-out were observed early in the postoperative period and required reoperation. Follow-up radiographs demonstrated evidence of fusion. Screw malposition was observed in one case (close to the disc space) (Fig. 2). A plate fracture following one-level corpectomy was observed in one case, 8 months after operation, in which there was evidence of solid bone fusion. There was only one case of bone nonunion. 


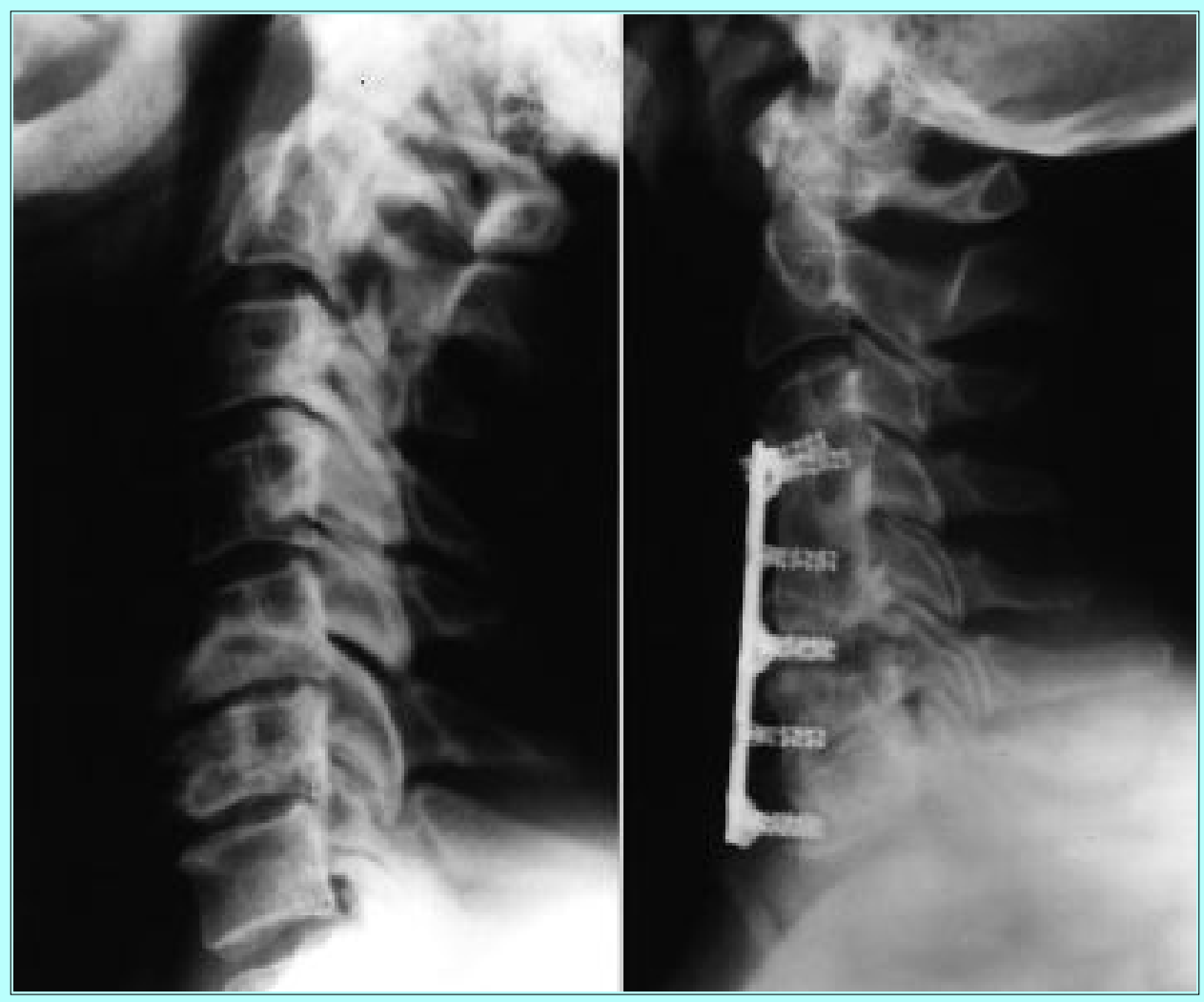

Fig. 3. Preoperative (left) and postoperative (right) radiographs obtained in a patient with CSM. Note fusion (with settling and angulation) and back-out of the caudal aspect of the plate.

Screw back-out was observed following a one-level corpectomy in one case (one [4.3\%] of 23), a two-level corpectomy in one case immediately after operation (one [6.6\%] of 15), and a three-level corpectomy in two cases (two [33.3\%] of six) (Fig. 3). All of the screw back-outs occurred with the Synthes system.

There were five reoperations. One patient underwent reoperation immediately after his first operation (two-level corpectomy) because of screw back-out and minimal movement of the graft. A second patient underwent reoperation because of nonunion, and a third because of screw malposition. The fourth patient underwent reoperation because of instrument failure in a long construct. This patient had previously undergone a laminectomy and lateral mass plating. The fifth patient underwent reoperation upon for removal of a broken cervical plate. 


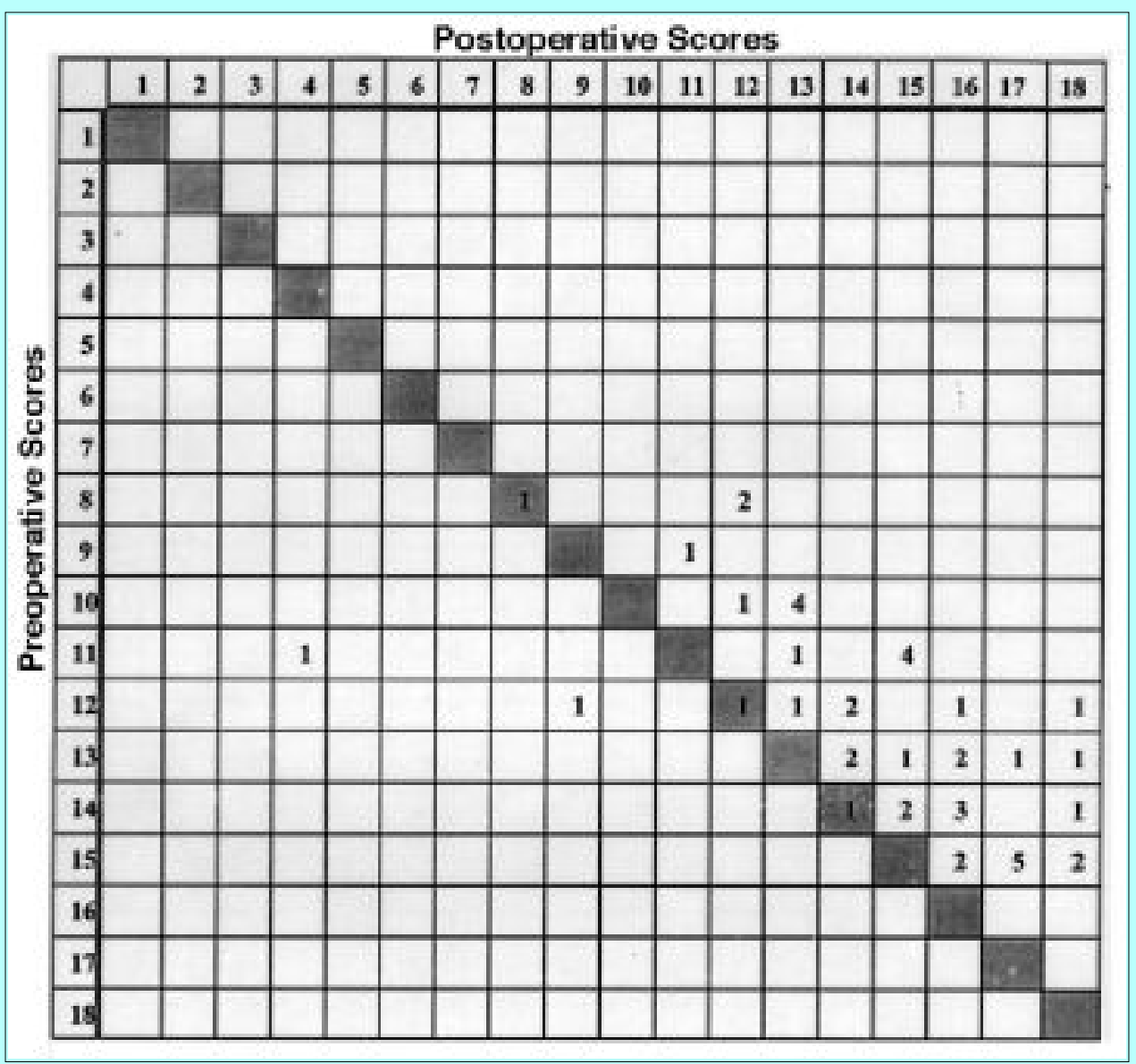

Fig. 4. Graph plotting the preoperative and postoperative functional results in patients according to the modified JOA scale.

The follow-up period ranged from 7 months to 60 months (mean 42.3 months). Overall, the fusion rate was $97.7 \%$. Three patients $(6.8 \%)$ showed no functional change, two patients $(4.54 \%)$ were worse, and 39 patients $(88.6 \%)$ showed functional improvement in their score (between +1 and +6 points; mean 2.16) (Fig. 4). The functional improvement score in patients 59 years and younger was between -7 and +6 points (mean $+2.172 \pm 2.522$ ), and in patients 60 years and older it was between +1 and +4 points $($ mean $+2.071 \pm 1.141)$. This difference was not found to be statistically significant. The mean improvement in the functional score was $+2.409 \pm 2.482$ (the case of the anoxic insult is included), $+2.400 \pm 1.454$, and $+0.5000 \pm 1.871$ following one-level, two-level, and three-level corpectomy, respectively. There was a statistically significant improvement when comparing patients who had undergone a one-level and three-level corpectomy, as well as a two-level and three-level corpectomy ( $\mathrm{p}<$ 0.05 ). There was no statistically significant difference between one-level and two-level corpectomy ( $\mathrm{p}>$ $0.05)$. If the anoxic injury is excluded, and this patient's last neurological score before hypoxic insult is used, the mean improvement of the one-level corpectomy is $+2.857 \pm 1.352$. In this situation, the comparison of neurological outcome between one-level and three-level corpectomy demonstrates a more significant statistical difference $(\mathrm{p}<0.01)$.

Two patients experienced a functional decline. Although the first patient exhibited a good result immediately after surgery (functional score of 11), he deteriorated due to cardiopulmonary compromise complicated by severe cerebral hypoxia. The late postoperative functional score for this patient was less than his preoperative score (preoperative 11 vs. postoperative 4). The second patient's operation was uneventful. However, he awakened from anesthesia with a new neurological deficit (preoperative score of 12 vs. postoperative score of 9). Postoperative imaging demonstrated no abnormality. Late follow-up 
evaluation revealed slow neurological recovery. The functional response to surgical intervention in all patients is depicted in Fig. 4.

One patient died 2 months after operation due to adenocarcinoma. In retrospect, the patient's preoperative symptoms may have been, in part, related to a paraneoplastic syndrome.

\section{DISCUSSION}

A variety of factors have been shown to affect the results of ventral cervical decompressive surgery for CSM including age, preoperative neurological condition and its chronicity, and the number of stenotic cervical spine segments.[2,4,14,20] An overall rate of $88.6 \%$ neurological status improvement after operation, with an improvement in the modified JOA scale between +1 and +6 points (mean +2.16$)$, was observed here.

The mean rate of improvement of the modified JOA scale score was found to be $+2.857 \pm 1.352$ (excluding the late result of the anoxic injury case), $+2.400 \pm 1.454$, and $+0.5000 \pm 0.871$, following one-level, two-level and three-level corpectomies, respectively. There was a statistically significant improvement when comparing patients who had undergone a one-level and three-level corpectomy ( $\mathrm{p}<$ $0.01)$, as well as a two-level and three-level corpectomy ( $\mathrm{p}<0.05)$. There was no statistically significant difference between one-level and two-level corpectomy $(\mathrm{p}>0.05)$.

The rate of improvement was $+2.172 \pm 2.522$, and $+2.071 \pm 1.141$ in patients 59 years old and younger and 60 years old and older, respectively. This difference was not found statistically to be significant ( $\mathrm{p}>$ $0.05)$.

The rate of neurological improvement for patients with CSM undergoing ventral surgical decompression has been reported to be 39 to $83 \%$.[7,14] Recently, Connolly, et al.,[7] reported an 83\% rate of neurological improvement. They reported neurological improvement rates of $83 \%, 73 \%$, and $66 \%$ following one-level, two-level, and three-level corpectomy, respectively, with grafting and plating. The rate of improvement following corpectomy and grafting (without plating), however, was found to be $100 \%$ and $70 \%$ following one-level and two-level corpectomy, respectively. They concluded that the overall clinical outcome of the patients was not improved with cervical plating.

Ventral cervical surgery may be associated with a number of neurological and nonneurological complications, as well as graft- and instrumentation-related complications. In this series, three respiratory complications (one pulmonary embolism, one hypersecretion, and one obstruction of upper airway) were observed. All three cases required reintubation. Two of them improved following appropriate medical treament.

Emery, et al.,[8] reported seven patients with obstruction of the upper airway immediately after ventral cervical spine surgery, and each required reintubation. The predominant causes of respiratory problems following ventral cervical surgery include laryngospasm, hematoma, paralysis of the vocal cords, allergic reaction, and edema. The possibility of upper airway obstruction following multilevel corpectomies necessitates additional caution in the postoperative period.

One of the patients in this series suffered neurological deterioration without an obvious cause. The postoperative imaging studies showed no evidence of focal neurological injury. Yonenobu, et al.,[19] reported neurological deterioration in five of 51 patients following corpectomy. 
The rate of graft- and instrumentation-related complications, as well as the rate of nonunion, increases as the length of the fusion increases.[5,6,9,10,13,19,21] The rate of nonunion has been reported to be 0 to $70 \%$ following multilevel corpectomy without plating, especially in patients undergoing fusion with allograft.[7,9,21] Yonenobu, et al.,[19] reported nonunion rates of 5\% and 45\% following one-level and three-level corpectomy respectively, using autografts. Fernyhough, et al.,[9] reported a total autograft nonunion rate of $27 \%$ and a total allograft nonunion rate of $41 \%$ for ventral cervical fusion in cases with cervical spondylosis. In their series, the rate of nonunion was $25 \%$ and $8 \%$ following two motion segment fusion, $22 \%$ and $43 \%$ following three motion segment fusion, and as high as $41 \%$ and $70 \%$ following four motion segment fusion using autograft and allograft, respectively. Using allograft, Zdeblick and Ducker[21] reported 5\% and 63\% nonunion rates following one-level and two-level fusion, respectively.

On the other hand, the rate of fusion in our series is greater than $90 \%$ in patients undergoing fusion with graft plus plate ( only one case of nonunion was observed). The rate of successful fusion is apparently increased by using instrumentation, especially with multiple corpectomies $[7,19]$.

The use of instrumentation in multilevel corpectomies decreases the rate of graft migration (intrusion and extrusion).[7] The use of instrumentation following ventral cervical surgery is, however, associated with instrumentation-related complications, such as screw back-out, screw malposition, and esophageal fistulas. In this series, screw back-out was observed in four patients $(9.3 \%)$ and screw malposition was observed in one patient $(2.3 \%)$. There was no esophageal, tracheal, or vascular injury secondary to instrumentation-related complications.

The results of this series demonstrate a relatively high rate of surgical, instrumentation-related complications; however, a high rate of fusion and functional (neurological) improvement was also observed. Although the rate of fusion in this series is good, the relatively high rate of instrumentation-related complications dictates careful consideration of the risk/benefit ratio in each patient.

\section{References}

1. Batzdorf U, Batzdorff A: Analysis of cervical spine curvature in patients with cervical spodylosis. Neurosurgery 22:827-836, 1988

\section{Benzel EC: Biomechanics of Spine Stabilization: Principles and Clinical Practice. New York:} McGraw-Hill, 1995

3. Benzel EC, Lancon J, Kesterson L, et al: Cervical laminectomy and dentate ligament section for cervical spondylotic myelopathy. J Spin Disord 4:286-295, 1991

4. Bernard TN, Whitecloud TS: Cervical spondylotic myelopathy and myeloradiculopathy. Anterior decompression and stabilization with autogenous fibula strut graft. Orthop Clin 221:149-160, 1987

5. Boni M, Cherubino P, Denaro V, et al: Multiple subtotal somatectomy. Technique and evaluation of a series of 39 cases. Spine 9:358-362, 1984

6. Caspar W: Anterior stabilization with trapezoid osteosynthetic plate technique in cervical spine injuries, in Kehr P and Weidner A (eds): Cervical Spine I. New York: Springer-Verlag, 1987, pp $198-202$ 
7. Connolly PJ, Esses SI, Kostuik JP: Anterior cervical fusion: outcome analysis of patients fused with and without anterior cervical plates. J Spinal Disord 9:202-206, 1996

8. Emery SE, Smith MD, Bohlman HH, et al: Upper-airway obstruction after multilevel cervical corpectomy for myelopathy. J Bone Joint Surg 73 (Am):544-551, 1991

9. Fernyhough JC, White JI, LaRocca H: Fusion rates in multilevel spondylosis comparing allograft fibula with autograft fibula in 126 patients. Spine 16 (Suppl 10):S561-S564, 1991

10. Herkowitz HN: Internal fixation for degenerative cervical spine disorders. Semin Spine Surg 7:57-60, 1995

11. Mann KS, Khosla VK, Gulati DR: Cervical spondylotic myelopathy treated by single-stage multilevel anterior decompression. A prospective study. J Neurosurg 60:81-87, 1984

12. Mayfield FH: Cervical spondylosis: a comparison of the anterior and posterior approaches. Clin Neurosurg 13:181-188, 1965

13. McAfee PC, Bohlman HH, Ducker TB, et al: One-stage anterior cervical decompression and posterior stabilization. A study of one hundred patients with a minimum of two years of follow up. $\mathbf{J}$ Bone Joint Surg 77 (Am): 1791-1800, 1995

14. Rowland LP: Surgical treatment of cervical spondylotic myelopathy: time for a controlled trial. Neurology 42:5-13, 1992

15. Samii M, Voelkening D, Sepehrnia A, et al: Surgical treatment of myeloradiculopathy in cervical spondylosis. A report on 438 operations. Neurosurg Rev 12:285-290, 1989

16. Seifert V, Stolke D: Multisegmental cervical spondylosis: treament by spondylectomy, microsurgical decompression, and osteosynthesis. Neurosurgery 29:498-503, 1991

17. Whitecloud TS: Anterior surgery for cervical spondylotic myelopathy. Smith-Robinson, Cloward, and vertebrectomy. 13:861-863, 1988

18. Yonenobu K, Fuji T, Ono K, et al: Choice of surgical treament for multisegmental cervical spondylotic myelopathy. Spine 10:710-716, 1985

19. Yonenobu K, Hosono N, Iwasaki M, et al: Laminoplasty versus subtotal corpectomy. A comparative study of results in multisegmental cervical spondylotic myelopathy. Spine 17:1281-1284, 1992

20. Yonenobu K, Hosono N, Iwasaki M, et al: Neurologic complications of surgery for cervical compression myelopathy. Spine 16:1277-1282, 1991

21. Zdeblick TA, Ducker TB: The use of freeze-dried allograft bone for anterior cervical fusions. Spine 16:726-729, 1991

Manuscript received November 8, 1996.

Accepted in final form November 14, 1996.

Address reprint requests to: Edward C. Benzel, M.D., Division of Neurosurgery, University of New Mexico School of Medicine, Albuquerque, New Mexico 87131-5341.

Click here to view Commentary on article 5. 